\title{
Structural and functional imaging markers for susceptibility to psychosis
}

\author{
Christina Andreou ${ }^{1,2} \cdot$ Stefan Borgwardt $\mathbb{D}^{1,2}$
}

Received: 4 November 2019 / Revised: 15 January 2020 / Accepted: 31 January 2020 / Published online: 17 February 2020

(c) The Author(s) 2020. This article is published with open access

\begin{abstract}
The introduction of clinical criteria for the operationalization of psychosis high risk provided a basis for early detection and treatment of vulnerable individuals. However, about two-thirds of people meeting clinical high-risk (CHR) criteria will never develop a psychotic disorder. In the effort to increase prognostic precision, structural and functional neuroimaging have received growing attention as a potentially useful resource in the prediction of psychotic transition in CHR patients. The present review summarizes current research on neuroimaging biomarkers in the CHR state, with a particular focus on their prognostic utility and limitations. Large, multimodal/multicenter studies are warranted to address issues important for clinical applicability such as generalizability and replicability, standardization of clinical definitions and neuroimaging methods, and consideration of contextual factors (e.g., age, comorbidity).
\end{abstract}

\section{Introduction}

Psychotic disorders pose a major challenge for psychiatric practice and public health, affecting several aspects of functioning and quality of life and being among the leading causes of disease burden worldwide [1]. Antipsychotic medication efficacy remains stable at a moderate effect size despite the introduction of several new antipsychotics [2], and recovery rates have not improved in the past 70 years [3].

In the 1990s, a paradigm shift in psychosis conceptualization and research led to an increased focus on the early stages of psychotic disorders, including the period before the onset of overt symptoms [4]. The introduction of clinical criteria for the operationalization of psychosis high risk provided a basis for early detection and treatment of vulnerable individuals, with the ultimate goal to improve outcomes by delaying or preventing the onset of psychotic disorders, and/or ensuring timely treatment.

Stefan Borgwardt

stefan.borgwardt@uksh.de

1 Department of Psychiatry and Psychotherapy, University of Lübeck, Lübeck, Germany

2 Department of Psychiatry (UPK), University of Basel, Basel, Switzerland
Currently, diagnosis of a clinical high-risk state is usually made based on ultra-high-risk (UHR) criteria, requiring the presence of either (a) positive symptoms that are typical of psychotic disorders but of subthreshold severity (attenuated psychotic symptoms; APS) or duration (brief limited intermittent psychotic symptoms; BLIPS), or (b) genetic high risk accompanied by functional decline (GRD) [5, 6]. A complementary approach focuses on basic symptoms [6], i.e., subjective changes in perception, cognition, and language that are conceptually less closely related to psychotic symptoms and have been suggested to indicate an earlier risk stage than UHR criteria [7].

Individuals meeting high-risk criteria are at substantially higher risk for developing a psychotic disorder compared with the general population [4, 8]. Most transitions occur within 2-3 years from initial assessment $[4,8,9]$ and result in a schizophrenia spectrum disorder [10]. However, with a sensitivity of $96 \%$ but only modest specificity of $47 \%$ [11], clinical high-risk criteria are more useful for excluding, rather than predicting, a future outcome of psychosis [12]. About two-thirds of individuals meeting high-risk criteria will not develop a psychotic disorder [4]; accordingly, there is substantial criticism to the psychosis high-risk paradigm, pointing out issues such as the lack of prognostic precision, specificity for psychosis, and the potential for unnecessary (self-)stigmatization and unindicated antipsychotic drug treatment in individuals receiving a diagnosis of high psychosis risk [13-15]. 
Given the above limitations of clinical high-risk criteria, there have been intensive efforts to improve specificity and predictive accuracy with respect to transition to psychosis using individual symptom profiles [16, 17], demographic [18], or cognitive variables [19]. In this context, structural and functional neuroimaging have received growing attention as a potentially useful resource in the prediction of psychotic transitions, as psychotic disorders are linked to several well-established abnormalities of brain structure and function. It is expected that neuroimaging can complement clinical judgment by providing standardized, objective biomarkers for predicting transition in high-risk individuals. The present review summarizes current research on neuroimaging biomarkers with a particular focus on their prognostic utility and limitations.

\section{Structural neuroimaging}

\section{Gray matter}

Gray matter abnormalities are probably the best studied neuroimaging biomarker in high-risk patients so far. Early MRI investigations used manual tracing to investigate regions of interest assumed to be affected in psychotic disorders. In contrast, more recent studies have mainly relied on automated approaches, which have the advantage of allowing group comparisons at the whole-brain level rather than specific regions [20, 21], thus being better suited for investigation of the complex neuroanatomical abnormalities expected to occur in patients with psychotic disorders. The most common such approach is voxel-based morphometry (VBM), which assesses between-group differences in regional volume or tissue composition based on estimates of tissue probability on a voxel-wise basis, as opposed to predefined anatomical borders [22]. It should be noted, though, that VBM is very sensitive to image registration procedures, and there is an ongoing debate on whether apparent volumetric changes may in fact reflect changes in position in some cases, especially given sulcal patterning abnormalities in patients with schizophrenia $[23,24]$. Volumetric approaches can be therefore complemented by surface-based techniques that assess measures such as cortical thickness [25], surface area [26] or gyrification (i.e., cortical folding) [27]. Evidence suggests that the characteristic convolutions of the cortical surface emerge through the axonal tension produced by neuronal connections during brain development in the 2nd and 3rd trimester of pregnancy [28]. Interestingly, different surface-based measures are differentially affected by genes and neurodevelopmental stage $[29,30]$. Therefore, these additional measures may additionally contribute to a more refined understanding of the neurodevelopmental abnormalities postulated to underlie psychotic disorders.
Several volumetric differences in gray matter have been reported in high-risk patients compared with healthy controls, the most consistent being volume reductions in hippocampal/parahippocampal areas, cingulate cortex, as well as the medial and lateral frontal cortex and medial parietal cortex [21, 31-33]. Studies comparing high-risk subjects with (CHR-T) and without (CHR-NT) later transition to psychosis indicates that some of these volume reductions might be relevant for the prediction of future psychotic transition. Although there is some variability in findings, certain areas have been repeatedly been shown to be associated with later psychosis in high-risk subjects. These include the anterior cingulate [34-36], frontal cortex [35, 37, 38], temporal cortex [34, 35, 37, 39], parietal cortex $[38,39]$, cerebellum [35, 37], and insular cortex [34, 40]. Moreover, CHR-T show larger pituitary volumes than CHR-NT [41]. Somewhat surprisingly given the prominent place of hippocampal dysfunction in theories of schizophrenia pathophysiology [42], findings are less consistent with respect to hippocampal areas and psychotic transition: three studies reported reduced hippocampal volume in CHR-T compared with CHR-NT [35, 43, 44]; however, others failed to find any differences in hippocampal volume [45-49] or cortical thickness [50] between the two patient groups. Beyond volumetric differences, a recent study [51] reported aberrant structural covariance patterns in the salience, executive control, auditory and motor networks in CHR-T compared with CHR-NT; although differences were subtle, they are consistent with reports of functional connectivity abnormalities in CHR patient populations (see below).

Beyond static comparisons, evidence suggests that the dynamic of changes in brain morphology over time might also be informative for predicting transition in CHR patients. CHR-T have been reported to exhibit greater longitudinal volume reduction and/or cortical thinning in frontal areas, including orbitofrontal, superior frontal, middle frontal, and prefrontal cortices [35, 37, 52-54]; temporal areas such as the inferior [37] and middle temporal cortex [55], and the fusiform and parahippocampal cortex [35]; the cingulate cortex $[35,55,56]$; the cerebellum [35, 37]; the medial and superior parietal lobes [37] and precuneus [55]; and the insular cortex [40]. These findings appear to be independent of antipsychotic medication treatment, as they did not differ between UHR patients with and without antipsychotic drug exposure [54], and are consistent with the notion of neurodevelopmental abnormalities leading to the emergence of psychotic disorders; however, they may also result from a range of other factors such as substance abuse, stress due to increased symptom load, or pharmacological treatment $[21,57]$. The effects of such confounding factors have not yet been systematically assessed. 


\section{White matter}

White matter density and regional distribution are agesensitive, and its development continues well into late adolescence and beyond [58]. Therefore, white matter studies in CHR patients might help elucidate abnormal neurodevelopmental trajectories in psychotic disorders.

The most widely used technique to assess white matter integrity is diffusion tensor imaging (DTI), which measures the diffusion of water molecules through tissues using T2weighted images in diverse directions. Although volumebased measures of white matter integrity similar to those for gray matter are available, track-based statistics are much more popular due to their superior accuracy [59]. The most common DTI-derived marker of white tract integrity is fractional anisotropy (FA), which provides an estimate of the net directionality of diffusion independent of fiber orientation. FA decreases reflect changes in neural fiber density, axon diameter, and myelination [60-62] but do not allow inferences about the nature of alterations (e.g., axonal degeneration, demyelination, or simply low signal-to-noise ratio) [63]. Such information is provided by indices of diffusion magnitude, i.e., axial (AD), radial (RD), and mean (MD) diffusivity, which are therefore important complementary measures to FA. For instance, axonal degeneration may be expressed in reduction in $\mathrm{FA}$ and $\mathrm{AD}$, along with an increase in $\mathrm{MD}$ and $\mathrm{RD}$, whereas demyelination displays a similar pattern, but without a change in AD [64].

FA is generally lowered in multiple brain regions in patients with schizophrenia [58]. CHR have been reported to display reduced whole white matter volume [65] as well as decreased FA the inferior fronto-occipital fasciculus (IFOF) and the inferior longitudinal fasciculus connecting the anterior temporal to the occipital lobe [66, 67], the superior longitudinal fasciculus that connects the frontal to the superior temporal, occipital and cerebellar cortices through the inferior parietal lobe and the supermarginal gyrus [66, 68, 69], and the corpus callosum [66, 69, 70]. Abnormal thalamocortical connectivity, considered to be one of the core pathologies in psychotic disorders, has also been reported in CHR patients, particularly affecting thalamus-orbitofrontal [71] and frontal-striatal-thalamic connections [72]; reduction in these thalamocortical tracts correlated with symptom severity and global social functioning, respectively [71, 72].

Unfortunately, there are few and inconsistent findings regarding diffusivity indices as a complement to FA $[66,73,74]$. Similarly, few studies have investigated the association of white matter changes in CHR with later transition to psychosis, and their findings are heterogeneous. Bloemen et al. [69] reported decreased FA in the superior temporal lobe and lateral putamen, but increased FA values in the medial temporal lobe in CHR-T compared with CHR-NT, whereas Peters et al. [75] found no differences between groups. On the other hand, Wood et al. [76] reported longer $\mathrm{T} 2$ relaxation times (which they used as an indicator of white matter pathology) in CHR-T compared with CHR-NT in the left hippocampal head, and this increase was correlated with psychotic symptom severity. It might be that differences in age (see also further below) and/or time of scanning contribute to these disparate findings: some longitudinal studies failed to find white matter differences between CHR-T and CHR-NT at baseline but reported differences at follow-up [55, 69, 77], while another study [78] reported higher frontal white matter volume at baseline, but more prominent reduction in white matter volume in the left IFOF over time, in CHR-T.

\section{Multivariate approaches and machine learning}

Currently, most neuroimaging studies in psychiatry rely on traditional mass-univariate statistical approaches. While these approaches are useful for detecting features that differentiate between groups, they cannot be used to infer whether an individual patient belongs to a certain group (e.g., CHR-T or CHR-NT) [79]. Therefore, in recent years there has been increased interest for machine-learning methods, which grew out of work in the artificial intelligence field. Machine learning uses a "training" set of existing data to develop mathematical functions that describe complex patterns in the data (i.e., "learn" from experience), which can then be used to make predictions on new data [80]. "Learning" in this context can be supervised or unsupervised: in the first case, the correct classification or outcome is used to train the algorithm, while unsupervised approaches seek to discover structure in the data without any other previous input [81]. Machine-learning models allow inferences at the individual level based on multivariate data with potentially intercorrelated features (a typical example is a spam email filter), and are therefore of great interest in the prediction of psychosis in high-risk patients.

Four studies have used support vector machines, a supervised machine-learning technique, to predict transition to psychosis in CHR patients based on neuroanatomical features [82-85], in partially overlapping patient samples from two CHR centers. In all studies, the pattern that predicted classification was not confined to single regions, but rather extended throughout the brain. Regions reported to contribute most to the decision function included (a) lateral prefrontal $[82,85]$, medial frontal and cingulate, as well as orbitofrontal areas [82-84]; (b) medial, lateral [84, 85], and inferior temporal including parahippocampal areas [82, 85]; (c) right inferior parietal areas [83, 84]; (d) subcortical structures, most notably the thalamus $[82,85]$ and basal ganglia [83, 84]; and (e) the cerebellum [83-85]. 
All of the above studies yielded high classification accuracy $(80-88 \%)$, with positive predictive values of $78-100 \%$ and negative predictive values of $80-90 \%$, suggesting that machine-learning models might be a promising tool in increasing the reliability of transition prediction. However, certain limitations should be kept in mind when interpreting findings. The most important issue is overfitting, which occurs when a statistical model describes noise (i.e., residual variance) in the data rather than genuine effects of interest [79]; this results in very good performance of the model on the observed data, but poor generalizability to unseen data [81]. The high dimensionality of MRI data, with millions of predictor variables for each participant, in combination with modest sample sizes, makes it likely that overfitting may have been an issue in the above studies. Indeed, a recent review of machine-learning techniques in psychiatric neuroimaging studies [79] demonstrated that overall reported accuracy decreased with larger sample sizes. Thus, external validation of machine-learning algorithms in new, independent patient samples is essential for establishing their generalizability and usefulness in clinical practice; so far, there is no external validation for neuroanatomical models of transition to psychosis. Still, the above studies are important in that they show in principle that structural MRI data can be used to support clinical prediction of transition at the individual patient level.

Other implementations of machine-learning models include their use to investigate age-related maturation of brain structure, which has been reported to follow deviant patterns in CHR patients. The North American Prodrome Longitudinal study (NAPLS 2) used structural MRI scans [86] of healthy individuals $(n=190)$ to develop age prediction models, and subsequently calculated the gap between model-predicted age and chronological age in CHR patients $(n=380)$; the Personalized Prognostic Tools for Early Psychosis Management study (PRONIA) implemented a similar approach on neurocognitive performance data of 36 healthy individuals and $48 \mathrm{CHR}$ patients [87]. A larger "brain-age" gap in CHR patients, which was predictive of greater risk of transition to psychosis, was observed in the NAPLS 2 study [86]. The neurocognitive age gap ("CogAGE") in the PRONIA study was also significantly higher in CHR patients than healthy controls [87], and was associated with increased gray matter volume in frontotemporal areas and diffuse white matter reductions. CogAGE did not predict transition, although this may have been due to sample size issues limiting statistical power.

\section{Functional neuroimaging}

Functional MRI (fMRI) has been widely used in patients with psychotic disorders with the aim of identifying neurobiological substrates of the well-established cognitive impairments associated with the illness, its excellent spatial resolution and noninvasive accessibility substantially contributing to its popularity. Although earlier studies investigated regional activity patterns, recent studies increasingly focus on functional connectivity, i.e., the temporal correlation of activity between different brain areas.

A multitude of fMRI studies in CHR patients have reported abnormalities in brain regional activity and/or functional connectivity during a variety of cognitive tasks [88], including verbal memory and working memory [31, 89-91], verbal fluency [92, 93], social cognition [9496], as well as in the context of functions more directly implicated in the emergence of psychotic symptoms such as salience processing [97] and evidence gathering [98]. Notably, in many cases, neuroimaging abnormalities were observed even in the absence of differences in behavioral performance. However, these studies are difficult to integrate in a unifying framework given that regional activation profiles and their changes in the high-risk state may vary significantly depending on the assessed function and the specific task or contrast used; for example, CHR patients have been reported to show decreased activity in the middle frontal gyrus in the context of verbal working memory paradigms [31, 89, 90], but increased activity in the same area during verbal fluency tasks [93]. Moreover, very few studies have differences with respect to later transition status; Allen et al. [99] reported increased activation in the prefrontal cortex, midbrain, and left hippocampus as well as increased connectivity between the midbrain and the prefrontal cortex in CHR-T than CHR-NT, but this finding has not yet been replicated. A promising perspective in this field is opened by computational modeling approaches, which use generative models to describe individual task performance and associate it to neuroimaging data [100-102].

Beyond task-based studies, investigations of the restingstate of the brain have been gaining substantial attention in the past two decades, based on findings suggesting that brain activity at rest is not random, and that instead it is organized in functionally meaningful spatiotemporal structures significance [103-107] that affect stimulus processing [105]. Resting-state fMRI studies in CHR patients have reported several disturbances in resting-state networks that are implicated in psychotic disorders, such as decreased coupling within the salience network [72]; dorsostriatal [108, 109], superior temporal [110], and thalamic dysconnectivity; and dysregulated activation of the default mode network [111, 112] including reduced anticorrelations with the task-positive [113, 114] and the salience network [113, 115]. With respect to later psychotic transition, aberrant thalamic connectivity has been reported to be more prominent in CHR-T compared with CHR-NT patients [116]. 


\section{Neurotransmitter systems}

Positron emission tomography (PET), single photon emission computed tomography, and magnetic resonance spectroscopy (MRS) allow the assessment of neurotransmitter system functionality at the molecular level, and thus are extremely useful in illuminating illness mechanisms, especially with a view to developing pharmacological treatment options. PET and MRS studies in CHR patients have focused on the dopamine and the glutamate system, given the relevance of these two neurotransmitter systems and their interactions for schizophrenia [117].

There are mixed results regarding dopamine availability in CHR; while some studies reported increased dopamine synthesis [99, 118, 119], which was specific to CHR-T in one study [120], other studies failed to find differences in dopamine synthesis capacity [121, 122], D2/D3 receptor availability [123], and synaptic dopamine concentration [124] between CHR and healthy controls. Still, even negative studies in CHR have reported abnormalities such as anomalous associations between dopamine synthesis and verbal memory performance [121] or salience processing [122], as well as reduced positive symptoms following dopamine depletion challenge [124]. Thus, some degree of dopaminergic dysfunction in the high-risk state with potential relevance for later psychotic transition appears plausible. Unfortunately, currently available imaging techniques do not allow differentiation between tonic and phasic aspects of dopaminergic neurotransmission, which are of particular interest given that they are assumed to be differentially affected in psychotic disorders [125].

Markers of glutamatergic neurotransmission such as glutamate and glutamine [generated from glutamate in glia cells [126]] have also been reported to show regional abnormalities in CHR patients, with reduced concentrations in the thalamus [93, 127-129] and elevated concentrations in the prefrontal cortex [129, 130] and the striatum [131]; the latter finding was associated with later transition. With respect to the hippocampus, findings are inconsistent $[129,132,133]$. However, a small study reported a negative association between hippocampal glutamate levels and striatal DOPA uptake in CHR patients $(n=16)$, which was not present in the healthy control sample $(n=12)$ and predicted on a trend level later transition to psychosis [132].

\section{Electrophysiology}

Electrophysiological methods such electroencephalography (EEG) and magnetoencephalography (MEG) have been less prominent than MRI-based techniques in early CHR research. However, advances in analysis techniques and the use of dense array configurations that help to enhance spatial resolution have renewed interest in EEG and MEG in recent years. Advantages of these methods are their excellent temporal resolution, which enables the investigation of the fast dynamics of neuronal interactions occurring on a millisecond time-scale [134], and the possibility to study neuronal network activity in a frequency-specific manner [135-138]. Moreover, emerging evidence suggests that certain neurophysiological measures might reveal coupling patterns that are not captured by fMRI [105]. Therefore, EEG and MEG may be useful complements to structural and functional MRI in disentangling the neurobiological origins of psychotic disorders.

Several neurophysiological biomarkers for schizophrenia have been identified, including early and late event-related potentials (ERP) and other measures of neural oscillatory activity [for reviews, see [139, 140]]. Among these, the best replicated findings concern mismatch negativity. The amplitude of this early preattentive ERP, which is of particular interest because of its association with glutamatergic neurotransmission [140] and the prediction error hypothesis of psychosis [141], is reduced in CHR patients [139, 140]. This reduction has been consistently found to predict transition to psychosis [142-145] with the exception of one study [146] in which, however, statistical power was limited by extremely low transition rates in the CHR group. Another ERP of interest is P300, which is modulated both by the glutamate/GABA [147] and the dopamine system [148]. P300 is also attenuated in CHR [149-153], correlating with gray and white matter abnormalities in these patients [154, 155], and was found to predict future transition in two studies [149, 156]. Gamma-band oscillations are also of potential interest due to their link to the feedback loop between parvalbumin-positive GABAergic interneurons and glutamatergic pyramidal cells [157, 158]. Oscillatory responses in this frequency band are also decreased in CHR [159-161] but have not yet been assessed with respect to later transition; aberrant resting-state gamma-band power has been also reported to predict psychotic transition in CHR patients [162]. Interestingly, EEG synchronization measures in the gamma band are not different between CHR patients and healthy controls, although aberrant synchronization has been observed in lower frequency bands [163-165].

\section{Discussion}

Since the introduction of clinical high-risk criteria in the 1990s, a huge body of structural and functional neuroimaging studies has advanced our understanding of mechanisms associated with risk for, and resilience to, psychotic disorders. Recent studies focus on the utility of structural and functional neuroimaging to improve prediction of 
outcomes in the individual patient. The findings summarized in the current review testify to the potential of neuroimaging tools as a complement to clinical assessment for quantifying the risk of transition to psychosis in CHR patients. However, several outstanding issues remain, which we address below.

\section{Data acquisition and preprocessing}

Neuroimaging data are collected on special equipment and undergo some extent of data preprocessing. Differences in acquisition parameters or preprocessing protocols may have nontrivial consequences on final results. Common examples include the effect of MRI scanner field strength and manufacturer [166], preprocessing steps such as segmentation, smoothing, and normalization of MRI data [167, 168], or the effects of filtering [169] or wavelet parameters [170] on EEG data. Multicenter studies use harmonized protocols and/or calibration procedures to minimize unwanted variance limiting statistical power $[9,50,171,172]$. Still, differences in data acquisition and preprocessing may limit comparability between different studies.

\section{Clinical definitions of CHR state and transition}

The diagnosis of both the CHR state and transition to psychosis rely on clinical instruments, which may vary across CHR centers and studies. Although there is substantial diagnostic agreement [173] between the two most widely used clinical instruments for CHR assessment [the Comprehensive Assessment of At-Risk Mental States (CAARMS) [5] and the Structured Interview of Prodromal Syndromes (SIPS) [174]], they differ with respect to their diagnostic threshold for psychosis, such that some patients categorized as CHR in the CAARMS may meet the criteria for a first psychotic episode in SIPS [173]. Moreover, their equivalence to other instruments [e.g., early recognition inventory ERIraos [175]] has not yet been assessed; neither is it clear how inclusion of CHR patients based on additional criteria [e.g., basic symptoms such as cognitiveperceptive basic symptoms or cognitive disturbances as assessed with the Schizophrenia Proneness Instrument [176, 177], or unspecific risk criteria [178]] may affect findings. An additional issue is that the prognostic accuracy of CHR criteria depends largely on pretest risk, which is higher for help-seeking patients than in the general population [11]. Thus, differences in recruitment setting (specialized early detection center vs. community) may result in substantial differences in participant samples. Finally, an important source of heterogeneity is follow-up duration: because the probability of transition increases with time in the first years from diagnosis [4, 8], studies with shorter follow-up periods are more likely to misclassify patients with later transitions, which might obscure between-group differences.

Another point to consider is that, even using the same diagnostic instrument, the CHR state is not a unitary concept. As detailed in "Introduction", there are several CHR subgroups, which differ in terms of not only phenomenology but also prognosis [179]. Further research is required to assess whether the differential expression of symptoms in these CHR groups may denote distinct neurobiological substrates.

\section{Age and developmental issues}

A major challenge in early psychosis neuroimaging research is that patients are at an age that is characterized, even in healthy individuals, by major neurodevelopmental changes in the brain. The most notable changes are gray matter loss and cortical thinning $[180,181]$ and changes in white matter volume and microstructure [182]. These effects conceivably confound results of statistical comparisons and predictive models. Unfortunately, the practice of using age as a covariate of no interest in statistical analyses is likely not sufficient to control for these effects, as changes in gray matter show nonlinear and regionally variable developmental patterns [30], while white matter volume and diffusivity follow different trajectories [182]. ERP biomarkers such as the P300 [183], MMN [184], and resting-state microstates [185] also undergo significant normative changes during development.

Two recent studies showcase the complex interactions of age with neuroanatomy and transition prediction. As detailed above, a larger gap between "brain age" and chronological age and was predictive of greater risk of transition to psychosis, was observed in the NAPLS 2 study; however, this effect was found only in patients diagnosed with CHR status at a young age (i.e., 12-17 years), while it was not present in patients diagnosed at a later age [86]. Another long-term follow-up study [186] reported that surface area decreases in the prefrontal, cingulate, and parahippocampal areas predicted poor symptomatic outcomes in younger, but not in older CHR adolescents. These findings highlight the need to consider patient age when comparing neuroanatomical findings across different studies.

\section{Power issues}

Many neuroimaging studies on CHR patients suffer from relatively small sample sizes, which might lead both to decreased power and increased probability for type II errors. A meta-analysis of studies in patients with established schizophrenia reported that the observed effect sizes with respect to reduction in gray matter structures was in the 
small to medium range ( $d=0.22$ to $d=0.58)$ [187]. The authors of the meta-analysis calculated that a sample size of $n=45$ in each group would be necessary to achieve adequate power with an effect size in the low medium range, yet the mean sample size of the studies included in the meta-analysis was only half this value. We observed a similar picture in the single-site studies included in this review, possibly because CHR patients are still underrepresented in clinical referrals for specialized treatment [188]. Moreover, transition rates of $\sim 26 \%$ within 3 years from diagnosis [11] result in small CHR-T sample sizes and/or uneven group sizes for comparisons between CHR-T and CHR-NT patients, further reducing statistical power.

\section{Multiform psychopathology}

Most CHR patients suffer from at least one nonpsychotic psychiatric disorder, most often substance-related, affective or anxiety disorders $[189,190]$, and it has been suggested that APS may be a transdiagnostic indicator of serious psychopathology regardless of transition risk [13]. The presence of multiform psychopathology may contribute additional variance to brain abnormalities observed in CHR patients, but has been rarely considered in neuroimaging studies of the CHR state and transition risk.

\section{Multimodal-multicenter approaches}

Although reviews [191-193] have emphasized superior potential of studies integrating data from different imaging modalities (e.g., functional and structural MRI, or MRI and PET) for obtaining new insights into the neuronal bases of psychotic disorders, such studies are still limited. Moreover, it should be kept in mind that the etiology of psychotic disorders is multifactorial, involving neurobiological and cognitive abnormalities in the context of diverse influencing factors such as genetics, the physical environment, and live events. Thus, models that assess multiple factors and their interactions with each other and time will be informative for theories of symptom emergence, progression, and resolution in CHR patients.

Given the necessity for data-driven, multimodal approaches and adequately powered studies, recently there has been a growing trend toward multicenter research projects. The inclusion of large patient samples and the integration of information across centers and modalities (e.g., neurobiology, genetics, neuropsychology and metacognition, clinical assessment, geo-socio-demographic information) in such projects not only provides better statistical power, but also enables a big-data approach that may contribute to systematic mapping of psychosis development mechanisms and to the development of supplementary diagnostic and/or prognostic tools. Four large multicenter projects are currently implementing such multimodal approaches with a focus on neurobiology and cognition (PRONIA, PSYSCAN), geneenvironment interactions (EU-GEI), or combinations of biological data such as neuroimaging, electrophysiology, endocrinology and genomics (NAPLS).

\section{Limitations and outlook}

The present review focused on predictors of psychotic transition in CHR patients. However, several other outcomes are equally relevant for clinical practice. CHR patients who do not develop psychosis suffer from high rates of psychiatric morbidity, persistent subclinical psychotic symptoms, and functional deficits [189, 190, 194, 195]. Several interesting studies have investigated neuroimaging markers of quantitative progression of multi-dimensional symptomatology [50, 186] or poor functional outcome [186, 196-198]. Moreover, given that so far there has been little evidence to favor any one specific intervention for preventing transition to psychosis [199], research into predictors of differential response to different interventions is of great relevance.

On a final note, an important conceptual issue is that the studies we reviewed here define transition to psychosis based on clinical assessment. Hence, the best that can be expected from any of the current predictive models is to replicate clinical diagnostic labels [cf. Viera et al. [81]]. However, as we detailed above, these labels are themselves arbitrary, inconsistent among instruments [200], and do not reflect the complexity of the clinical picture and needs of CHR patients. Implementing bottom-up, multimodal approaches that cut across categorical diagnoses and can help reconceptualize diagnostic classifications represents a greater challenge, and a potential new perspective for neuroimaging in the high-risk state.

\section{Conclusions}

The past two decades of CHR research were exceptionally productive, leading to substantial insights into illness mechanisms leading to psychotic disorders. Still, several issues need to be addressed to achieve clinical applicability, including standardization of clinical definitions and neuroimaging methods, increased focus on generalizability and replicability, and increased attention to contextual factors such as age and comorbidity. The "second wave" of CHR research we are currently experiencing is characterized by large, multimodal/multicenter studies that make use of advances in computing techniques to generate findings that will be useful for individualized prediction in the context of precision psychiatry.

Acknowledgements Open access funding provided by Projekt DEAL. 


\section{Compliance with ethical standards}

Conflict of interest The authors declare that they have no conflict of interest.

Publisher's note Springer Nature remains neutral with regard to jurisdictional claims in published maps and institutional affiliations.

Open Access This article is licensed under a Creative Commons Attribution 4.0 International License, which permits use, sharing, adaptation, distribution and reproduction in any medium or format, as long as you give appropriate credit to the original author(s) and the source, provide a link to the Creative Commons license, and indicate if changes were made. The images or other third party material in this article are included in the article's Creative Commons license, unless indicated otherwise in a credit line to the material. If material is not included in the article's Creative Commons license and your intended use is not permitted by statutory regulation or exceeds the permitted use, you will need to obtain permission directly from the copyright holder. To view a copy of this license, visit http://creativecommons. org/licenses/by/4.0/.

\section{References}

1. Vos T, CJL Murray, Collaborators GDaIIaP Global, regional, and national incidence, prevalence, and years lived with disability for 328 diseases and injuries for 195 countries, 19902016: a systematic analysis for the Global Burden of Disease Study 2016. Lancet. 2017;390:1211-59.

2. Leucht S, Arbter D, Engel RR, Kissling W, Davis JM. How effective are second-generation antipsychotic drugs? A metaanalysis of placebo-controlled trials. Mol Psychiatry. 2009;14:429-47.

3. Jaaskelainen E, Juola P, Hirvonen N, McGrath JJ, Saha S, Isohanni $\mathrm{M}$, et al. A systematic review and meta-analysis of recovery in schizophrenia. Schizophr Bull. 2013;39:1296-306.

4. Fusar-Poli P, Borgwardt S, Bechdolf A, Addington J, RiecherRossler A, Schultze-Lutter F, et al. The psychosis high-risk state: a comprehensive state-of-the-art review. JAMA Psychiatry. 2013;70:107-20.

5. Yung AR, Pan Yuen H, Mcgorry PD, Phillips LJ, Kelly D, Dell'olio M, et al. Mapping the onset of psychosis: the comprehensive assessment of at-risk mental states. Aust N.Z. J Psychiatry. 2005;39:964-71.

6. Klosterkötter J, Schultze-Lutter F, Bechdolf A, Ruhrmann S. Prediction and prevention of schizophreniA: What has been achieved and where to go next? World Psychiatry. 2011;10:165-74.

7. Schultze-Lutter F, Ruhrmann S, Berning J, Maier W, Klosterkotter J. Basic symptoms and ultrahigh risk criteria: symptom development in the initial prodromal state. Schizophr Bull. 2010;36:182-91.

8. Schultze-Lutter F, Michel C, Schmidt SJ, Schimmelmann BG, Maric NP, Salokangas RK, et al. EPA guidance on the early detection of clinical high risk states of psychoses. Eur Psychiatry. 2015;30:405-16.

9. Kempton MJ, McGuire P. How can neuroimaging facilitate the diagnosis and stratification of patients with psychosis? Eur Neuropsychopharmacol. 2015;25:725-32.

10. Fusar-Poli P, Bechdolf A, Taylor MJ, Bonoldi I, Carpenter WT, Yung AR, et al. At risk for schizophrenic or affective psychoses? A meta-analysis of DSM/ICD diagnostic outcomes in individuals at high clinical risk. Schizophr Bull. 2013;39:923-32.
11. Fusar-Poli P, Cappucciati M, Rutigliano G, Schultze-Lutter F, Bonoldi I, Borgwardt S, et al. At risk or not at risk? A metaanalysis of the prognostic accuracy of psychometric interviews for psychosis prediction. World Psychiatry. 2015;14:322-32.

12. Fusar-Poli P, Schultze-Lutter F. Predicting the onset of psychosis in patients at clinical high risk: Practical guide to probabilistic prognostic reasoning. Evid Based Ment Health. 2016;19:10-5.

13. van Os J, Guloksuz S. A critique of the "ultra-high risk" and "transition" paradigm. World Psychiatry. 2017;16:200-6.

14. Moritz S, Gaweda L, Heinz A, Gallinat J. Four reasons why early detection centers for psychosis should be renamed and their treatment targets reconsidered: we should not catastrophize a future we can neither reliably predict nor change. Psychol Med. 2019;49:2134-40.

15. Yung AR, Woods SW, Ruhrmann S, Addington J, SchultzeLutter F, Cornblatt BA, et al. Whither the attenuated psychosis syndrome? Schizophr Bull. 2012;38:1130-4.

16. Mechelli A, Lin A, Wood S, McGorry P, Amminger P, Tognin $\mathrm{S}$, et al. Using clinical information to make individualized prognostic predictions in people at ultra high risk for psychosis. Schizophr Res. 2017;184:32-8.

17. Ruhrmann S, Schultze-Lutter F, Salokangas RK, Heinimaa M, Linszen D, Dingemans P, et al. Prediction of psychosis in adolescents and young adults at high risk: results from the prospective European prediction of psychosis study. Arch Gen Psychiatry. 2010;67:241-51.

18. Fusar-Poli P, Rutigliano G, Stahl D, Davies C, Bonoldi I, Reilly $\mathrm{T}$, et al. Development and validation of a clinically based risk calculator for the transdiagnostic prediction of psychosis. JAMA Psychiatry. 2017;74:493-500.

19. Fusar-Poli P, Deste G, Smieskova R, Barlati S, Yung AR, Howes $\mathrm{O}$, et al. Cognitive functioning in prodromal psychosis: a metaanalysis. Arch Gen Psychiatry. 2012;69:562-71.

20. Scarpazza C, Tognin S, Frisciata S, Sartori G, Mechelli A. False positive rates in voxel-based morphometry studies of the human brain: should we be worried? Neurosci Biobehav Rev. 2015;52:49-55.

21. Bois C, Whalley HC, McIntosh AM, Lawrie SM. Structural magnetic resonance imaging markers of susceptibility and transition to schizophrenia: a review of familial and clinical high risk population studies. J Psychopharmacol. 2015;29:144-54.

22. Ashburner J, Friston KJ. Voxel-based morphometry-the methods. Neuroimage. 2000;11:805-21.

23. Agnew-Blais J, Seidman LJ. Neurocognition in youth and young adults under age 30 at familial risk for schizophrenia: a quantitative and qualitative review. Cogn Neuropsychiatry. 2013;18:44-82.

24. Palaniyappan L, Liddle PF. Differential effects of surface area, gyrification and cortical thickness on voxel based morphometric deficits in schizophrenia. Neuroimage. 2012;60:693-9.

25. Dale AM, Fischl B, Sereno MI. Cortical surface-based analysis. I. Segmentation and surface reconstruction. Neuroimage. 1999;9:179-94.

26. Fischl B, Sereno MI, Dale AM. Cortical surface-based analysis. II: inflation, flattening, and a surface-based coordinate system. Neuroimage. 1999;9:195-207.

27. Schaer M, Cuadra MB, Tamarit L, Lazeyras F, Eliez S, Thiran JP. A surface-based approach to quantify local cortical gyrification. IEEE Trans Med Imaging. 2008;27:161-70.

28. White T, Hilgetag CC. Gyrification and neural connectivity in schizophrenia. Dev Psychopathol. 2011;23:339-52.

29. Panizzon MS, Fennema-Notestine C, Eyler LT, Jernigan TL, Prom-Wormley E, Neale M, et al. Distinct genetic influences on cortical surface area and cortical thickness. Cereb Cortex. 2009;19:2728-35. 
30. Wierenga LM, Langen M, Oranje B, Durston S. Unique developmental trajectories of cortical thickness and surface area. Neuroimage. 2014;87:120-6.

31. Fusar-Poli P, Broome MR, Woolley JB, Johns LC, Tabraham P, Bramon $\mathrm{E}$, et al. Altered brain function directly related to structural abnormalities in people at ultra high risk of psychosis: longitudinal VBM-fMRI study. J Psychiatr Res. 2011;45:190-8.

32. Smieskova R, Fusar-Poli P, Aston J, Simon A, Bendfeldt K, Lenz $\mathrm{C}$, et al. Insular volume abnormalities associated with different transition probabilities to psychosis. Psychol Med. 2012;42:1613-25.

33. Hunter SA, Lawrie SM. Imaging and genetic biomarkers predicting transition to psychosis. Curr Top Behav Neurosci. 2018;40:353-88.

34. Meijer JH, Schmitz N, Nieman DH, Becker HE, van Amelsvoort TA, Dingemans PM, et al. Semantic fluency deficits and reduced grey matter before transition to psychosis: a voxelwise correlational analysis. Psychiatry Res. 2011;194:1-6.

35. Pantelis C, Velakoulis D, McGorry PD, Wood SJ, Suckling J, Phillips LJ, et al. Neuroanatomical abnormalities before and after onset of psychosis: a cross-sectional and longitudinal MRI comparison. Lancet. 2003;361:281-8.

36. Walterfang M, Yung A, Wood AG, Reutens DC, Phillips L, Wood SJ, et al. Corpus callosum shape alterations in individuals prior to the onset of psychosis. Schizophr Res. 2008;103:1-10.

37. Borgwardt SJ, McGuire PK, Aston J, Gschwandtner U, Pfluger MO, Stieglitz RD, et al. Reductions in frontal, temporal and parietal volume associated with the onset of psychosis. Schizophr Res. 2008;106:108-14.

38. Dazzan P, Soulsby B, Mechelli A, Wood SJ, Velakoulis D, Phillips LJ, et al. Volumetric abnormalities predating the onset of schizophrenia and affective psychoses: an MRI study in subjects at ultrahigh risk of psychosis. Schizophr Bull. 2012;38:1083-91.

39. Borgwardt SJ, McGuire PK, Aston J, Berger G, Dazzan P, Gschwandtner U, et al. Structural brain abnormalities in individuals with an at-risk mental state who later develop psychosis. $\mathrm{Br}$ J Psychiatry Suppl. 2007;51:s69-75.

40. Takahashi T, Wood SJ, Yung AR, Phillips LJ, Soulsby B, McGorry PD, et al. Insular cortex gray matter changes in individuals at ultra-high-risk of developing psychosis. Schizophr Res. 2009;111:94-102.

41. Nordholm D, Krogh J, Mondelli V, Dazzan P, Pariante C, Nordentoft M. Pituitary gland volume in patients with schizophrenia, subjects at ultra high-risk of developing psychosis and healthy controls: a systematic review and meta-analysis. Psychoneuroendocrinology. 2013;38:2394-404.

42. Lieberman JA, Girgis RR, Brucato G, Moore H, Provenzano F, Kegeles L, et al. Hippocampal dysfunction in the pathophysiology of schizophrenia: a selective review and hypothesis for early detection and intervention. Mol Psychiatry. 2018;23:1764-72.

43. Mechelli A, Riecher-Rossler A, Meisenzahl EM, Tognin S, Wood SJ, Borgwardt SJ, et al. Neuroanatomical abnormalities that predate the onset of psychosis: a multicenter study. Arch Gen Psychiatry. 2011;68:489-95.

44. Witthaus H, Mendes U, Brune M, Ozgurdal S, Bohner G, Gudlowski Y, et al. Hippocampal subdivision and amygdalar volumes in patients in an at-risk mental state for schizophrenia. $\mathrm{J}$ Psychiatry Neurosci. 2010;35:33-40.

45. Velakoulis D, Wood SJ, Wong MT, McGorry PD, Yung A, Phillips L, et al. Hippocampal and amygdala volumes according to psychosis stage and diagnosis: a magnetic resonance imaging study of chronic schizophrenia, first-episode psychosis, and ultra-highrisk individuals. Arch Gen Psychiatry. 2006;63:139-49.

46. Walter A, Studerus E, Smieskova R, Kuster P, Aston J, Lang UE, et al. Hippocampal volume in subjects at high risk of psychosis: a longitudinal MRI study. Schizophr Res. 2012;142:217-22.
47. Buehlmann E, Berger GE, Aston J, Gschwandtner U, Pflueger MO, Borgwardt SJ, et al. Hippocampus abnormalities in at risk mental states for psychosis? A cross-sectional high resolution region of interest magnetic resonance imaging study. J Psychiatr Res. 2010;44:447-53.

48. Walter A, Suenderhauf C, Harrisberger F, Lenz C, Smieskova R, Chung Y, et al. Hippocampal volume in subjects at clinical highrisk for psychosis: a systematic review and meta-analysis. Neurosci Biobehav Rev. 2016;71:680-90.

49. Wood SJ, Yucel M, Velakoulis D, Phillips LJ, Yung AR, Brewer $\mathrm{W}$, et al. Hippocampal and anterior cingulate morphology in subjects at ultra-high-risk for psychosis: the role of family history of psychotic illness. Schizophr Res. 2005;75:295-301.

50. Tognin S, Riecher-Rossler A, Meisenzahl EM, Wood SJ, Hutton C, Borgwardt SJ, et al. Reduced parahippocampal cortical thickness in subjects at ultra-high risk for psychosis. Psychol Med. 2014;44:489-98.

51. Heinze K, Reniers RL, Nelson B, Yung AR, Lin A, Harrison BJ, et al. Discrete alterations of brain network structural covariance in individuals at ultra-high risk for psychosis. Biol Psychiatry. 2015;77:989-96.

52. Cannon TD, Cadenhead K, Cornblatt B, Woods SW, Addington $\mathrm{J}$, Walker E, et al. Prediction of psychosis in youth at high clinical risk: a multisite longitudinal study in North America. Arch Gen Psychiatry. 2008;65:28-37.

53. Sun D, Phillips L, Velakoulis D, Yung A, McGorry PD, Wood SJ, et al. Progressive brain structural changes mapped as psychosis develops in 'at risk' individuals. Schizophr Res. 2009;108:85-92.

54. Cannon TD. How schizophrenia develops: cognitive and brain mechanisms underlying onset of psychosis. Trends Cogn Sci. 2015;19:744-56.

55. Ziermans TB, Schothorst PF, Schnack HG, Koolschijn PC, Kahn RS, van Engeland H, et al. Progressive structural brain changes during development of psychosis. Schizophr Bull. 2012;38:519-30.

56. Fornito A, Yung AR, Wood SJ, Phillips LJ, Nelson B, Cotton S, et al. Anatomic abnormalities of the anterior cingulate cortex before psychosis onset: an MRI study of ultra-high-risk individuals. Biol Psychiatry. 2008;64:758-65.

57. Wood SJ, Reniers RL, Heinze K. Neuroimaging findings in the at-risk mental state: a review of recent literature. Can J Psychiatry. 2013;58:13-8.

58. Peters BD, Karlsgodt KH. White matter development in the early stages of psychosis. Schizophr Res. 2015;161:61-9.

59. Smith SM, Jenkinson M, Johansen-Berg H, Rueckert D, Nichols TE, Mackay CE, et al. Tract-based spatial statistics: voxelwise analysis of multi-subject diffusion data. Neuroimage. 2006;31:1487-505.

60. Basser PJ, Pierpaoli C. Microstructural and physiological features of tissues elucidated by quantitative-diffusion-tensor MRI. J Magn Reson B. 1996;111:209-19.

61. Beaulieu C. The basis of anisotropic water diffusion in the nervous system - a technical review. NMR Biomed. 2002;15:435-55.

62. Bartzokis G, Beckson M, Lu PH, Nuechterlein KH, Edwards N, Mintz J. Age-related changes in frontal and temporal lobe volumes in men: a magnetic resonance imaging study. Arch Gen Psychiatry. 2001;58:461-5.

63. Pierpaoli C, Basser PJ. Toward a quantitative assessment of diffusion anisotropy. Magn Reson Med. 1996;36:893-906.

64. Alexander AL, Hurley SA, Samsonov AA, Adluru N, Hosseinbor AP, Mossahebi P, et al. Characterization of cerebral white matter properties using quantitative magnetic resonance imaging stains. Brain Connect. 2011;1:423-46.

65. Witthaus H, Brune M, Kaufmann C, Bohner G, Ozgurdal S, Gudlowski Y, et al. White matter abnormalities in subjects at 
ultra high-risk for schizophrenia and first-episode schizophrenic patients. Schizophr Res. 2008;102:141-9.

66. Rigucci S, Santi G, Corigliano V, Imola A, Rossi-Espagnet C, Mancinelli I, et al. White matter microstructure in ultra-high risk and first episode schizophrenia: a prospective study. Psychiatry Res. 2016;247:42-8.

67. Epstein KA, Cullen KR, Mueller BA, Robinson P, Lee S, Kumra $\mathrm{S}$. White matter abnormalities and cognitive impairment in earlyonset schizophrenia-spectrum disorders. J Am Acad Child Adolesc Psychiatry. 2014;53:362-72.e1-2.

68. Karlsgodt KH, Niendam TA, Bearden CE, Cannon TD. White matter integrity and prediction of social and role functioning in subjects at ultra-high risk for psychosis. Biol Psychiatry. 2009;66:562-9.

69. Bloemen OJ, de Koning MB, Schmitz N, Nieman DH, Becker HE, de Haan L, et al. White-matter markers for psychosis in a prospective ultra-high-risk cohort. Psychol Med. 2010;40:1297-304.

70. Katagiri N, Pantelis C, Nemoto T, Zalesky A, Hori M, Shimoji K, et al. A longitudinal study investigating sub-threshold symptoms and white matter changes in individuals with an 'at risk mental state' (ARMS). Schizophr Res. 2015;162:7-13.

71. Cho KI, Shenton ME, Kubicki M, Jung WH, Lee TY, Yun JY, et al. Altered thalamo-cortical white matter connectivity: probabilistic tractography study in clinical-high risk for psychosis and first-episode psychosis. Schizophr Bull. 2016;42:723-31.

72. Wang C, Ji F, Hong Z, Poh JS, Krishnan R, Lee J, et al. Disrupted salience network functional connectivity and white-matter microstructure in persons at risk for psychosis: findings from the LYRIKS study. Psychol Med. 2016;46:2771-83.

73. Schmidt A, Lenz C, Smieskova R, Harrisberger F, Walter A, Riecher-Rossler A, et al. Brain diffusion changes in emerging psychosis and the impact of state-dependent psychopathology. Neurosignals. 2015;23:71-83.

74. von Hohenberg CC, Pasternak O, Kubicki M, Ballinger T, Vu MA, Swisher T, et al. White matter microstructure in individuals at clinical high risk of psychosis: a whole-brain diffusion tensor imaging study. Schizophr Bull. 2014;40:895-903.

75. Peters BD, Dingemans PM, Dekker N, Blaas J, Akkerman E, van Amelsvoort TA, et al. White matter connectivity and psychosis in ultra-high-risk subjects: a diffusion tensor fiber tracking study. Psychiatry Res. 2010;181:44-50.

76. Wood SJ, Kennedy D, Phillips LJ, Seal ML, Yucel M, Nelson B, et al. Hippocampal pathology in individuals at ultra-high risk for psychosis: a multi-modal magnetic resonance study. Neuroimage. 2010;52:62-8.

77. Carletti F, Woolley JB, Bhattacharyya S, Perez-Iglesias R, Fusar Poli P, Valmaggia L, et al. Alterations in white matter evident before the onset of psychosis. Schizophr Bull. 2012;38:1170-9.

78. Walterfang M, McGuire PK, Yung AR, Phillips LJ, Velakoulis $\mathrm{D}$, Wood SJ, et al. White matter volume changes in people who develop psychosis. Br J Psychiatry. 2008;193:210-5.

79. Arbabshirani MR, Plis S, Sui J, Calhoun VD. Single subject prediction of brain disorders in neuroimaging: Promises and pitfalls. Neuroimage. 2017;145:137-65.

80. Mitchell T. Machine learning. New York, NY: McGraw-Hill; 1998.

81. Vieira S, Pinaya WH, Mechelli A. Using deep learning to investigate the neuroimaging correlates of psychiatric and neurological disorders: methods and applications. Neurosci Biobehav Rev. 2017;74:58-75.

82. Koutsouleris N, Borgwardt S, Meisenzahl EM, Bottlender R, Moller HJ, Riecher-Rossler A. Disease prediction in the at-risk mental state for psychosis using neuroanatomical biomarkers: results from the FePsy study. Schizophr Bull. 2012;38:1234-46.

83. Koutsouleris N, Riecher-Rossler A, Meisenzahl EM, Smieskova R, Studerus E, Kambeitz-Ilankovic L, et al. Detecting the psychosis prodrome across high-risk populations using neuroanatomical biomarkers. Schizophr Bull. 2015;41:471-82.

84. Zarogianni E, Storkey AJ, Borgwardt S, Smieskova R, Studerus E, Riecher-Rossler A, et al. Individualized prediction of psychosis in subjects with an at-risk mental state. Schizophr Res. 2019;214:18-23.

85. Koutsouleris N, Meisenzahl EM, Davatzikos C, Bottlender R, Frodl T, Scheuerecker J, et al. Use of neuroanatomical pattern classification to identify subjects in at-risk mental states of psychosis and predict disease transition. Arch Gen Psychiatry. 2009;66:700-12.

86. Chung Y, Allswede D, Addington J, Bearden CE, Cadenhead K, Cornblatt B, et al. Cortical abnormalities in youth at clinical high-risk for psychosis: findings from the NAPLS2 cohort. Neuroimage Clin. 2019;23:101862.

87. Kambeitz-Ilankovic L, Haas SS, Meisenzahl E, Dwyer DB, Weiske J, Peters H, et al. Neurocognitive and neuroanatomical maturation in the clinical high-risk states for psychosis: a pattern recognition study. Neuroimage Clin. 2019;21:101624.

88. Dutt A, Tseng HH, Fonville L, Drakesmith M, Su L, Evans J, et al. Exploring neural dysfunction in 'clinical high risk' for psychosis: a quantitative review of fMRI studies. J Psychiatr Res. 2015;61:122-34.

89. Schmidt A, Smieskova R, Simon A, Allen P, Fusar-Poli P, McGuire PK, et al. Abnormal effective connectivity and psychopathological symptoms in the psychosis high-risk state. J Psychiatry Neurosci. 2014;39:239-48.

90. Smieskova R, Allen P, Simon A, Aston J, Bendfeldt K, Drewe J, et al. Different duration of at-risk mental state associated with neurofunctional abnormalities. A multimodal imaging study. Hum Brain Mapp. 2012;33:2281-94.

91. Fusar-Poli P, Broome MR, Matthiasson P, Woolley JB, Johns LC, Tabraham P, et al. Spatial working memory in individuals at high risk for psychosis: longitudinal fMRI study. Schizophr Res. 2010;123:45-52.

92. Broome MR, Matthiasson P, Fusar-Poli P, Woolley JB, Johns LC, Tabraham P, et al. Neural correlates of executive function and working memory in the 'at-risk mental state'. Br J Psychiatry. 2009;194:25-33.

93. Fusar-Poli P, Stone JM, Broome MR, Valli I, Mechelli A, McLean MA, et al. Thalamic glutamate levels as a predictor of cortical response during executive functioning in subjects at high risk for psychosis. Arch Gen Psychiatry. 2011;68:881-90.

94. Modinos G, Tseng HH, Falkenberg I, Samson C, McGuire P, Allen P. Neural correlates of aberrant emotional salience predict psychotic symptoms and global functioning in high-risk and first-episode psychosis. Soc Cogn Affect Neurosci. 2015; 10:1429-36.

95. Seiferth NY, Pauly K, Habel U, Kellermann T, Shah NJ, Ruhrmann $S$, et al. Increased neural response related to neutral faces in individuals at risk for psychosis. Neuroimage. 2008;40:289-97.

96. van der Velde J, Opmeer EM, Liemburg EJ, Bruggeman R, Nieboer R, Wunderink $\mathrm{L}$, et al. Lower prefrontal activation during emotion regulation in subjects at ultrahigh risk for psychosis: an fMRI-study. NPJ Schizophr. 2015;1:15026.

97. Smieskova R, Roiser JP, Chaddock CA, Schmidt A, Harrisberger $\mathrm{F}$, Bendfeldt $\mathrm{K}$, et al. Modulation of motivational salience processing during the early stages of psychosis. Schizophr Res. 2015;166:17-23.

98. Rausch F, Mier D, Eifler S, Fenske S, Schirmbeck F, Englisch S, et al. Reduced activation in the ventral striatum during probabilistic decision-making in patients in an at-risk mental state. $\mathrm{J}$ Psychiatry Neurosci. 2015;40:163-73.

99. Allen P, Luigjes J, Howes OD, Egerton A, Hirao K, Valli I, et al. Transition to psychosis associated with prefrontal and subcortical 
dysfunction in ultra high-risk individuals. Schizophr Bull. 2012;38:1268-76.

100. Diaconescu AO, Hauke DJ, Borgwardt S. Models of persecutory delusions: a mechanistic insight into the early stages of psychosis. Mol Psychiatry. 2019;24:1258-67.

101. Stephan KE, Schlagenhauf F, Huys QJM, Raman S, Aponte EA, Brodersen $\mathrm{KH}$, et al. Computational neuroimaging strategies for single patient predictions. Neuroimage. 2017;145:180-99.

102. Fletcher PC, Frith CD. Perceiving is believing: a Bayesian approach to explaining the positive symptoms of schizophrenia. Nat Rev Neurosci. 2009;10:48-58.

103. Damoiseaux JS, Rombouts SA, Barkhof F, Scheltens P, Stam CJ, Smith SM, et al. Consistent resting-state networks across healthy subjects. Proc Natl Acad Sci USA. 2006;103:13848-53.

104. Engel AK, Fries P, Singer W. Dynamic predictions: oscillations and synchrony in top-down processing. Nat Rev Neurosci. 2001;2:704-16.

105. Engel AK, Gerloff C, Hilgetag CC, Nolte G. Intrinsic coupling modes: multiscale interactions in ongoing brain activity. Neuron. 2013;80:867-86.

106. Friston K. A theory of cortical responses. Philos Trans R Soc Lond B Biol Sci. 2005;360:815-36.

107. Fox MD, Snyder AZ, Vincent JL, Corbetta M, Van Essen DC, Raichle ME. The human brain is intrinsically organized into dynamic, anticorrelated functional networks. Proc Natl Acad Sci USA. 2005;102:9673-8.

108. Dandash O, Fornito A, Lee J, Keefe RS, Chee MW, Adcock RA, et al. Altered striatal functional connectivity in subjects with an at-risk mental state for psychosis. Schizophr Bull. 2014;40:904-13.

109. Hubl D, Schultze-Lutter F, Hauf M, Dierks T, Federspiel A, Kaess M, et al. Striatal cerebral blood flow, executive functioning, and fronto-striatal functional connectivity in clinical high risk for psychosis. Schizophr Res. 2018;201:231-6.

110. Yoon YB, Yun JY, Jung WH, Cho KI, Kim SN, Lee TY, et al. Altered fronto-temporal functional connectivity in individuals at ultra-high-risk of developing psychosis. PLoS ONE. 2015;10: e0135347.

111. Wotruba D, Heekeren K, Michels L, Buechler R, Simon JJ, Theodoridou A, et al. Symptom dimensions are associated with reward processing in unmedicated persons at risk for psychosis. Front Behav Neurosci. 2014;8:382.

112. Damme KSF, Pelletier-Baldelli A, Cowan HR, Orr JM, Mittal VA. Distinct and opposite profiles of connectivity during selfreference task and rest in youth at clinical high risk for psychosis. Hum Brain Mapp. 2019;40:3254-64.

113. Wotruba D, Michels L, Buechler R, Metzler S, Theodoridou A, Gerstenberg M, et al. Aberrant coupling within and across the default mode, task-positive, and salience network in subjects at risk for psychosis. Schizophr Bull. 2014;40:1095-104.

114. Shim G, Oh JS, Jung WH, Jang JH, Choi CH, Kim E, et al. Altered resting-state connectivity in subjects at ultra-high risk for psychosis: an fMRI study. Behav Brain Funct. 2010;6:58.

115. Pelletier-Baldelli A, Bernard JA, Mittal VA. Intrinsic functional connectivity in salience and default mode networks and aberrant social processes in youth at ultra-high risk for psychosis. PLoS ONE. 2015;10:e0134936.

116. Anticevic A, Haut K, Murray JD, Repovs G, Yang GJ, Diehl C, et al. Association of thalamic dysconnectivity and conversion to psychosis in youth and young adults at elevated clinical risk. JAMA Psychiatry. 2015;72:882-91.

117. Howes O, McCutcheon R, Stone J. Glutamate and dopamine in schizophrenia: an update for the 21st century. J Psychopharmacol. 2015;29:97-115.

118. Egerton A, Chaddock CA, Winton-Brown TT, Bloomfield MA, Bhattacharyya S, Allen P, et al. Presynaptic striatal dopamine dysfunction in people at ultra-high risk for psychosis: findings in a second cohort. Biol Psychiatry. 2013;74:106-12.

119. Howes OD, Montgomery AJ, Asselin MC, Murray RM, Valli I, Tabraham $P$, et al. Elevated striatal dopamine function linked to prodromal signs of schizophrenia. Arch Gen Psychiatry. 2009;66:13-20.

120. Howes OD, Bose SK, Turkheimer F, Valli I, Egerton A, Valmaggia LR, et al. Dopamine synthesis capacity before onset of psychosis: a prospective [18F]-DOPA PET imaging study. Am J Psychiatry. 2011;168:1311-7.

121. Allen P, Chaddock CA, Howes OD, Egerton A, Seal ML, FusarPoli $\mathrm{P}$, et al. Abnormal relationship between medial temporal lobe and subcortical dopamine function in people with an ultra high risk for psychosis. Schizophr Bull. 2012; 38:1040-9.

122. Roiser JP, Howes OD, Chaddock CA, Joyce EM, McGuire P. Neural and behavioral correlates of aberrant salience in individuals at risk for psychosis. Schizophr Bull. 2013;39:1328-36.

123. Suridjan I, Rusjan P, Addington J, Wilson AA, Houle S, Mizrahi R. Dopamine D2 and D3 binding in people at clinical high risk for schizophrenia, antipsychotic-naive patients and healthy controls while performing a cognitive task. J Psychiatry Neurosci. 2013;38:98-106.

124. Bloemen OJ, de Koning MB, Gleich T, Meijer J, de Haan L, Linszen DH, et al. Striatal dopamine D2/3 receptor binding following dopamine depletion in subjects at ultra high risk for psychosis. Eur Neuropsychopharmacol. 2013;23:126-32.

125. Maia TV, Frank MJ. An integrative perspective on the role of dopamine in schizophrenia. Biol Psychiatry. 2017;81:52-66.

126. Ramadan S, Lin A, Stanwell P. Glutamate and glutamine: a review of in vivo MRS in the human brain. NMR Biomed. 2013;26:1630-46.

127. Egerton A, Stone JM, Chaddock CA, Barker GJ, Bonoldi I, Howard RM, et al. Relationship between brain glutamate levels and clinical outcome in individuals at ultra high risk of psychosis. Neuropsychopharmacology. 2014;39:2891-9.

128. Allen P, Chaddock CA, Egerton A, Howes OD, Barker G, Bonoldi I, et al. Functional outcome in people at high risk for psychosis predicted by thalamic glutamate levels and prefrontostriatal activation. Schizophr Bull. 2015;41:429-39.

129. Stone JM, Day F, Tsagaraki H, Valli I, McLean MA, Lythgoe DJ, et al. Glutamate dysfunction in people with prodromal symptoms of psychosis: relationship to gray matter volume. Biol Psychiatry. 2009;66:533-9.

130. Liemburg E, Sibeijn-Kuiper A, Bais L, Pijnenborg G, Knegtering $\mathrm{H}$, van der Velde $\mathrm{J}$, et al. Prefrontal NAA and Glx levels in different stages of psychotic disorders: a 3T 1H-MRS study. Sci Rep. 2016;6:21873.

131. de la Fuente-Sandoval C, Leon-Ortiz P, Azcarraga M, Favila R, Stephano S, Graff-Guerrero A. Striatal glutamate and the conversion to psychosis: a prospective $1 \mathrm{H}-\mathrm{MRS}$ imaging study. Int J Neuropsychopharmacol. 2013;16:471-5.

132. Stone JM, Howes OD, Egerton A, Kambeitz J, Allen P, Lythgoe DJ, et al. Altered relationship between hippocampal glutamate levels and striatal dopamine function in subjects at ultra high risk of psychosis. Biol Psychiatry. 2010;68:599-602.

133. Nenadic I, Maitra R, Basu S, Dietzek M, Schonfeld N, Lorenz C, et al. Associations of hippocampal metabolism and regional brain grey matter in neuroleptic-naive ultra-high-risk subjects and first-episode schizophrenia. Eur Neuropsychopharmacol. 2015;25:1661-8.

134. Uhlhaas PJ. Dysconnectivity, large-scale networks and neuronal dynamics in schizophrenia. Curr Opin Neurobiol. 2013;23:283-90.

135. Hillebrand A, Barnes GR, Bosboom JL, Berendse HW, Stam CJ. Frequency-dependent functional connectivity within resting-state 
networks: an atlas-based MEG beamformer solution. Neuroimage. 2012;59:3909-21.

136. Hipp JF, Hawellek DJ, Corbetta M, Siegel M, Engel AK. Largescale cortical correlation structure of spontaneous oscillatory activity. Nat Neurosci. 2012;15:884-90.

137. Marzetti L, Della Penna S, Snyder AZ, Pizzella V, Nolte G, de Pasquale F, et al. Frequency specific interactions of MEG resting state activity within and across brain networks as revealed by the multivariate interaction measure. Neuroimage. 2013;79:172-83.

138. Andreou C, Frielinghaus H, Rauh J, Mußmann M, Vauth S, Braun $\mathrm{P}$, et al. Theta and high-beta networks for feedback processing: a simultaneous EEG-fMRI study in healthy male subjects. Transl Psychiatry. 2017;7:e1016.

139. Light GA, Swerdlow NR. Future clinical uses of neurophysiological biomarkers to predict and monitor treatment response for schizophrenia. Ann NY Acad Sci. 2015;1344:105-19.

140. Mikanmaa E, Grent-'t-Jong T, Hua L, Recasens M, Thune H, Uhlhaas PJ. Towards a neurodynamical understanding of the prodrome in schizophrenia. Neuroimage. 2019;190:144-53.

141. Garrido MI, Kilner JM, Kiebel SJ, Friston KJ. Dynamic causal modeling of the response to frequency deviants. J Neurophysiol. 2009;101:2620-31.

142. Bodatsch M, Ruhrmann S, Wagner M, Muller R, Schultze-Lutter F, Frommann I, et al. Prediction of psychosis by mismatch negativity. Biol Psychiatry. 2011;69:959-66.

143. Perez VB, Woods SW, Roach BJ, Ford JM, McGlashan TH, Srihari $\mathrm{VH}$, et al. Automatic auditory processing deficits in schizophrenia and clinical high-risk patients: forecasting psychosis risk with mismatch negativity. Biol Psychiatry. 2014;75:459-69.

144. Higuchi Y, Sumiyoshi T, Seo T, Miyanishi T, Kawasaki Y, Suzuki M. Mismatch negativity and cognitive performance for the prediction of psychosis in subjects with at-risk mental state. PLoS ONE. 2013;8:e54080.

145. Shaikh M, Valmaggia L, Broome MR, Dutt A, Lappin J, Day F, et al. Reduced mismatch negativity predates the onset of psychosis. Schizophr Res. 2012;134:42-8.

146. Atkinson RJ, Fulham WR, Michie PT, Ward PB, Todd J, Stain $\mathrm{H}$, et al. Electrophysiological, cognitive and clinical profiles of at-risk mental state: The longitudinal Minds in Transition (MinT) study. PLoS ONE. 2017;12:e0171657.

147. Watson TD, Petrakis IL, Edgecombe J, Perrino A, Krystal JH, Mathalon DH. Modulation of the cortical processing of novel and target stimuli by drugs affecting glutamate and GABA neurotransmission. Int $\mathrm{J}$ Neuropsychopharmacol. 2009;12:357-70.

148. Pogarell O, Padberg F, Karch S, Segmiller F, Juckel G, Mulert C, et al. Dopaminergic mechanisms of target detection - P300 event related potential and striatal dopamine. Psychiatry Res. 2011;194:212-8.

149. van Tricht MJ, Nieman DH, Koelman JH, van der Meer JN, Bour LJ, de Haan L, et al. Reduced parietal P300 amplitude is associated with an increased risk for a first psychotic episode. Biol Psychiatry. 2010;68:642-8.

150. Atkinson RJ, Michie PT, Schall U. Duration mismatch negativity and $\mathrm{P} 3 \mathrm{a}$ in first-episode psychosis and individuals at ultra-high risk of psychosis. Biol Psychiatry. 2012;71:98-104.

151. Bramon E, Shaikh M, Broome M, Lappin J, Berge D, Day F, et al. Abnormal P300 in people with high risk of developing psychosis. Neuroimage. 2008;41:553-60.

152. Lee SY, Namkoong K, Cho HH, Song DH, An SK. Reduced visual P300 amplitudes in individuals at ultra-high risk for psychosis and first-episode schizophrenia. Neurosci Lett. 2010;486:156-60.

153. Ozgurdal S, Gudlowski Y, Witthaus H, Kawohl W, Uhl I, Hauser M, et al. Reduction of auditory event-related P300 amplitude in subjects with at-risk mental state for schizophrenia. Schizophr Res. 2008;105:272-8.

154. Fusar-Poli P, Crossley N, Woolley J, Carletti F, Perez-Iglesias R, Broome $\mathrm{M}$, et al. White matter alterations related to P300 abnormalities in individuals at high risk for psychosis: an MRIEEG study. J Psychiatry Neurosci. 2011;36:239-48.

155. Fusar-Poli P, Crossley N, Woolley J, Carletti F, Perez-Iglesias R, Broome M, et al. Gray matter alterations related to P300 abnormalities in subjects at high risk for psychosis: longitudinal MRI-EEG study. Neuroimage. 2011;55:320-8.

156. Hamilton HK, Woods SW, Roach BJ, Llerena K, McGlashan $\mathrm{TH}$, Srihari VH, et al. Auditory and visual oddball stimulus processing deficits in schizophrenia and the psychosis risk syndrome: forecasting psychosis risk with P300. Schizophr Bull. 2019;45:1068-80.

157. Bartos M, Vida I, Jonas P. Synaptic mechanisms of synchronized gamma oscillations in inhibitory interneuron networks. Nat Rev Neurosci. 2007;8:45-56.

158. Sohal VS, Zhang F, Yizhar O, Deisseroth K. Parvalbumin neurons and gamma rhythms enhance cortical circuit performance. Nature. 2009;459:698-702.

159. Leicht G, Vauth S, Polomac N, Andreou C, Rauh J, Mußmann $\mathrm{M}$, et al. EEG-informed fMRI reveals a disturbed gamma-bandspecific network in subjects at high risk for psychosis. Schizophr Bull. 2016;42:239-49.

160. Tada M, Nagai T, Kirihara K, Koike S, Suga M, Araki T, et al. Differential alterations of auditory gamma oscillatory responses between pre-onset high-risk individuals and first-episode schizophrenia. Cereb Cortex. 2016;26:1027-35.

161. Perez VB, Roach BJ, Woods SW, Srihari VH, McGlashan TH, Ford JM, et al. Early auditory gamma-band responses in patients at clinical high risk for schizophrenia. Suppl Clin Neurophysiol. 2013;62:147-62.

162. Ramyead A, Studerus E, Kometer M, Uttinger M, Gschwandtner $\mathrm{U}$, Fuhr P, et al. Prediction of psychosis using neural oscillations and machine learning in neuroleptic-naive at-risk patients. World J Biol Psychiatry. 2016;17:285-95.

163. Andreou C, Faber PL, Leicht G, Schoettle D, Polomac N, Hanganu-Opatz IL, et al. Resting-state connectivity in the prodromal phase of schizophrenia: insights from EEG microstates. Schizophr Res. 2014;152:513-20.

164. Andreou C, Leicht G, Nolte G, Polomac N, Moritz S, Karow A, et al. Resting-state theta-band connectivity and verbal memory in schizophrenia and in the high-risk state. Schizophr Res. 2015;161:299-307.

165. Ramyead A, Kometer M, Studerus E, Koranyi S, Ittig S, Gschwandtner U, et al. Aberrant current source-density and lagged phase synchronization of neural oscillations as markers for emerging psychosis. Schizophr Bull. 2015;41:919-29.

166. Jovicich J, Czanner S, Han X, Salat D, van der Kouwe A, Quinn $\mathrm{B}$, et al. MRI-derived measurements of human subcortical, ventricular and intracranial brain volumes: reliability effects of scan sessions, acquisition sequences, data analyses, scanner upgrade, scanner vendors and field strengths. Neuroimage. 2009;46:177-92.

167. Ashburner J, Friston KJ. Why voxel-based morphometry should be used. Neuroimage. 2001;14:1238-43.

168. Smith SM, Nichols TE. Threshold-free cluster enhancement: addressing problems of smoothing, threshold dependence and localisation in cluster inference. Neuroimage. 2009;44:83-98.

169. Widmann A, Schroger E, Maess B. Digital filter design for electrophysiological data-a practical approach. J Neurosci Methods. 2015;250:34-46.

170. Roach BJ, Mathalon DH. Event-related EEG time-frequency analysis: An overview of measures and an analysis of early 
gamma band phase locking in schizophrenia. Schizophr Bull. 2008;34:907-26.

171. Cannon TD, Sun F, McEwen SJ, Papademetris X, He G, van Erp $\mathrm{TG}$, et al. Reliability of neuroanatomical measurements in a multisite longitudinal study of youth at risk for psychosis. Hum Brain Mapp. 2014;35:2424-34.

172. Schnack HG, van Haren NE, Brouwer RM, van Baal GC, Picchioni M, Weisbrod $\mathrm{M}$, et al. Mapping reliability in multicenter MRI: voxel-based morphometry and cortical thickness. Hum Brain Mapp. 2010;31:1967-82.

173. Fusar-Poli P, Cappucciati M, Rutigliano G, Lee TY, Beverly Q, Bonoldi I, et al. Towards a standard psychometric diagnostic interview for subjects at ultra high risk of psychosis: CAARMS versus SIPS. Psychiatry. 2016;2016:1-11.

174. McGlashan T, Walsch B, Woods S. The psychosis-risk syndrome. handbook for diagnosis and follow-up. New York, NY: Oxford University Press; 2010.

175. Maurer K, Zink M, Rausch F, Hafner H. The early recognition inventory ERIraos assesses the entire spectrum of symptoms through the course of an at-risk mental state. Early Inter Psychiatry. 2018;12:217-28.

176. Schultze-Lutter F, Addington J, Ruhrmann S, Klosterkotter J. Schizophrenia proneness instrument, adult version. Roma, Italy: Giovanni Fioriti Editore; 2007.

177. Schultze-Lutter F, Koch E. Schizophrenia proneness instrument, child \& youth version (SPI-CY). Roma, Italy: Giovanni Fioriti Editore; 2010.

178. Peralta D, Studerus E, Andreou C, Beck K, Ittig S, Leanza L, et al. Exploring the predictive power of the unspecific risk category of the basel screening instrument for psychosis. Early Inter Psychiatry. 2019;13:969-76.

179. Fusar-Poli P, Cappucciati M, Bonoldi I, Hui LM, Rutigliano G, Stahl DR, et al. Prognosis of brief psychotic episodes: a metaanalysis. JAMA Psychiatry. 2016;73:211-20.

180. Gogtay N, Giedd JN, Lusk L, Hayashi KM, Greenstein D, Vaituzis AC, et al. Dynamic mapping of human cortical development during childhood through early adulthood. Proc Natl Acad Sci USA. 2004;101:8174-9.

181. Tamnes CK, Herting MM, Goddings AL, Meuwese R, Blakemore SJ, Dahl RE, et al. Development of the cerebral cortex across adolescence: a multisample study of inter-related longitudinal changes in cortical volume, surface area, and thickness. J Neurosci. 2017;37:3402-12.

182. Lebel C, Deoni S. The development of brain white matter microstructure. Neuroimage. 2018;182:207-18.

183. Downes M, Bathelt J, De Haan M. Event-related potential measures of executive functioning from preschool to adolescence. Dev Med Child Neurol. 2017;59:581-90.

184. Corcoran CM, Stoops A, Lee M, Martinez A, Sehatpour P, Dias EC, et al. Developmental trajectory of mismatch negativity and visual event-related potentials in healthy controls: implications for neurodevelopmental vs. neurodegenerative models of schizophrenia. Schizophr Res. 2018;191:101-8.

185. Koenig T, Prichep L, Lehmann D, Sosa PV, Braeker E, Klein$\operatorname{logel} \mathrm{H}$, et al. Millisecond by millisecond, year by year: normative EEG microstates and developmental stages. Neuroimage. 2002;16:41-8.

186. de Wit S, Ziermans TB, Nieuwenhuis M, Schothorst PF, van Engeland H, Kahn RS, et al. Individual prediction of long-term outcome in adolescents at ultra-high risk for psychosis: applying machine learning techniques to brain imaging data. Hum Brain Mapp. 2017;38:704-14.

187. Haijma SV, Van Haren N, Cahn W, Koolschijn PC, Hulshoff Pol HE, Kahn RS. Brain volumes in schizophrenia: a meta-analysis in over 18000 subjects. Schizophr Bull. 2013;39:1129-38.

188. Ajnakina O, Morgan C, Gayer-Anderson C, Oduola S, Bourque F, Bramley S, et al. Only a small proportion of patients with first episode psychosis come via prodromal services: a retrospective survey of a large UK mental health programme. BMC Psychiatry. 2017;17:308.

189. Lin A, Wood SJ, Nelson B, Beavan A, McGorry P, Yung AR. Outcomes of nontransitioned cases in a sample at ultra-high risk for psychosis. Am J Psychiatry. 2015;172:249-58.

190. Michel C, Ruhrmann S, Schimmelmann BG, Klosterkötter J, Schultze-Lutter F. Course of clinical high-risk states for psychosis beyond conversion. Eur Arch Psychiatry Clin Neurosci. 2018;268:39-48.

191. Cabral C, Kambeitz-Ilankovic L, Kambeitz J, Calhoun VD, Dwyer DB, von Saldern S, et al. Classifying schizophrenia using multimodal multivariate pattern recognition analysis: evaluating the impact of individual clinical profiles on the neurodiagnostic performance. Schizophr Bull. 2016;42 Suppl 1:S110-7.

192. Radua J, Borgwardt S, Crescini A, Mataix-Cols D, MeyerLindenberg A, McGuire PK, et al. Multimodal meta-analysis of structural and functional brain changes in first episode psychosis and the effects of antipsychotic medication. Neurosci Biobehav Rev. 2012;36:2325-33.

193. Schultz CC, Fusar-Poli P, Wagner G, Koch K, Schachtzabel C, Gruber $\mathrm{O}$, et al. Multimodal functional and structural imaging investigations in psychosis research. Eur Arch Psychiatry Clin Neurosci. 2012;262 Suppl 2:S97-106.

194. Polari A, Lavoie S, Yuen HP, Amminger P, Berger G, Chen E, et al. Clinical trajectories in the ultra-high risk for psychosis population. Schizophr Res. 2018;197:550-6.

195. Beck K, Andreou C, Studerus E, Heitz U, Ittig S, Leanza L, et al. Clinical and functional long-term outcome of patients at clinical high risk (CHR) for psychosis without transition to psychosis: a systematic review. Schizophr Res. 2019;210:39-47.

196. Kambeitz-Ilankovic L, Meisenzahl EM, Cabral C, von Saldern S, Kambeitz J, Falkai P, et al. Prediction of outcome in the psychosis prodrome using neuroanatomical pattern classification. Schizophr Res. 2016;173:159-65.

197. Koutsouleris N, Kambeitz-Ilankovic L, Ruhrmann S, Rosen M, Ruef A, Dwyer DB, et al. Prediction models of functional outcomes for individuals in the clinical high-risk state for psychosis or with recent-onset depression: a multimodal, multisite machine learning analysis. JAMA Psychiatry. 2018;75:1156-72.

198. de Wit S, Wierenga LM, Oranje B, Ziermans TB, Schothorst PF, van Engeland $\mathrm{H}$, et al. Brain development in adolescents at ultrahigh risk for psychosis: longitudinal changes related to resilience. Neuroimage Clin. 2016;12:542-9.

199. Davies C, Cipriani A, Ioannidis J, Radua J, Stahl D, Provenzani $\mathrm{U}$, et al. Lack of evidence to favor specific preventive interventions in psychosis: a network meta-analysis. World Psychiatry. 2018;17:196-209.

200. Fusar-Poli P, Van OsJ. Lost in transition: setting the psychosis threshold in prodromal research. Acta Psychiatr Scand. 2013;127:248-52. 